\title{
Meninos na Educação Infantil: o olhar das educadoras sobre a diversidade de gênero*
}

\author{
Isabel de Oliveira e Silva** \\ Iza Rodrigues da Luz $z^{* * * *}$
}

\section{Resumo}

A Educação Infantil vem se consolidando como o momento de entrada das crianças no sistema educacional e, portanto, como condição que altera as formas de participação no espaço público no início da vida. Com uma abordagem que compreende a experiência individual e coletiva no espaço institucional como experiência de constituição dos sujeitos, o que inclui as aprendizagens - de si, do outro e do mundo - no contexto de relações das crianças entre si $e$ com os adultos, este artigo analisa as concepções de educadoras sobre a educação de meninos no contexto institucional. As informações construídas durante a pesquisa indicam que elas orientam-se por uma imagem de masculinidade que priva os meninos de maior contato corporal $e$ afetivo e de experiências significativas de convivência $e$ brincadeiras tidas como adequadas somente para as meninas.

Palavras-chave: Educação Infantil, Cuidados, Gênero, Meninos.

\footnotetext{
" Recebido para publicação em março de 2010, aceito em maio de 2010. Agradecemos a disponibilidade das educadoras da Educação Infantil que nos concederam entrevistas.

** Doutora em Educação, Professora da Faculdade de Educação da UFMG/Núcleo de Estudos Infância e Educação Infantil - NEPEI. isabel.os@uol.com.br

****Doutora em Educação, Professora da Faculdade de Educação da UFMG/Núcleo de Estudos Infância e Educação Infantil - NEPEI.

izaluz@bol.com.br
}

cadernos pagu (34), janeiro-junho de 2010:17-39. 
Meninos na Educação Infantil

\author{
Boys in Pre-School Education: \\ the Standpoint of Educators about Gender Diversity
}

\begin{abstract}
Pre-School education, the first phase of elementary education in Brazil, has been slowly consolidating as the entry of Brazilian children in the educational system and as a condition that changes the children's way of participating in the public arena at the very beginning of life. The growing tendency of expanding pre-school education implies a transformation of the moments, places and ways of socializing children early in their lives. This article aims at analyzing the conceptions of pre-school teachers in regard to the education of boys in the institutional sphere. It is based on a standpoint that conceives both the individual as well as the collective experiences in the institutional space as the foundation of the individuals, which involves learning about the self, about others and about the world itself. This article argues that the educators' perceptions of the differences between boys and girls reflect social stereotypes related to gender relations and that the changes in the educational practices inside the schools, however, come into conflict with the teachers' broader social experiences, including those of their family context.
\end{abstract}

Key Words: Children's Education, Care, Gender, Boys. 
Isabel de Oliveira e Silva e Iza Rodrigues da Luz

As crianças e suas experiências nos contextos escolares nos primeiros anos de vida vêm se constituindo em objetos do interesse de pesquisadores e pesquisadoras de diferentes campos, especialmente o da educação que, desde 1996 (BRASIL, 1996), incorporou, em sua legislação específica, a responsabilidade pelo cuidado e educação das crianças de zero até seis anos de idade.

De uma área de estudos que focalizou a criança inicialmente pelas faltas, sustentando suas análises nas idéias de carência e de preparação para a escolaridade futura, a Educação Infantil educação da criança de 0 a 6 anos - vem tomando, nos últimos anos, cada vez mais, as crianças - e a infância ou infâncias como sujeitos e como objeto a ser conhecido, por meio de lentes teóricas que se afastam de concepções essencialistas $e$ universalistas desses atores e dessa fase da vida (Rocha, 2007; Silva; Luz; Faria Filho, 2010).

Fruto de um movimento social que colocou as crianças no centro da cena pública, argüindo sua condição de sujeito de direitos (Craydy, 1994; Silva, 2008), a produção acadêmica da área da Educação Infantil vem procurando, nos últimos anos, analisar os processos vivenciados pelas crianças nas relações entre si e com os adultos em diferentes contextos, dentre os quais se encontram as instituições de Educação Infantil.

Embora a área de estudos ainda seja intensamente dominada pelas questões relativas às funções dessa etapa da educação - como a tradução do sentido de cuidar e educar para a construção de políticas públicas e práticas pedagógicas - o sujeito criança ganha espaço em um território em que, por vezes, essas mesmas práticas e políticas deflagram conflitos entre os interesses e necessidades das crianças e dos adultos por elas responsáveis familiares e professoras (Rosemberg, 2001). As reflexões de Faria (2006:282) expressam a complexidade desse ambiente:

Assim, com uma história completamente diferente da história da escola, a creche é um direito à educação também diferente. Ela é constituída por três atores: pais e 
Meninos na Educação Infantil

mães, professoras e crianças. Articula o direito à educação das crianças pequenas com o direito trabalhista dos seus pais e mães. Neste espaço da sociedade vivemos as mais distintas relações de poder: gênero, classe, idade e, lógico, étnicas. Ainda estão para serem melhor e mais estudadas e investigadas as relações no contexto da creche onde confrontam-se adultos - entre eles, professor/a, diretora, cozinheira, guarda, pai, mãe, secretário/a de educação, prefeito/a, vereador/a, etc. -; confrontam-se crianças, entre elas: menino, menina, mais velha, mais nova, negra, branca, judia, com necessidades especiais, pobre, rica, de classe média, católica, umbandista, atéia, "café com leite", "quatro olhos", etc; e confrontam-se adultos e crianças - a professora $e$ as meninas, a professora $e$ os meninos, o professor (percentual bastante baixo, mas existente e com tendência a lento crescimento) e os meninos, o professor $e$ as meninas, o professor e a mãe da menina...

Nesse ambiente, as experiências proporcionadas aos meninos e às meninas vêm sendo, cada vez mais, objeto da análise e da construção de propostas pedagógicas que orientem as políticas e as práticas das educadoras.

Questões de gênero perpassaram as análises da Educação Infantil informadas pelas questões relativas, de um lado, à igualdade de oportunidades para homens e mulheres - na medida em que os cuidados com os filhos restringem, nas nossas sociedades, as possibilidades de vida pública das mulheres - e, de outro, à maciça presença de mulheres entre as educadoras infantis e seus significados relativos às identidades profissionais na área (Silva, 2001; 2008). Nesse sentido, as relações de gênero estão presentes pela via das questões relativas ao feminino e aos sujeitos adultos (Rosemberg, 2001).

São poucos os estudos no Brasil que apresentam análises sobre as experiências das crianças na Educação Infantil tendo como perspectiva teórica - e política - a questão das diferenças e, em especial, a construção de masculinidades e feminilidades. 
Rocha (1999) constatou que nas pesquisas sobre educação da criança de 0 a 6 anos apresentadas em congressos até os anos 1990 não existiam estudos que analisassem as relações de gênero. Rosemberg (2001) destaca que somente 3\% das pesquisas apresentadas nas reuniões da Associação Nacional de PósGraduação Pesquisa em Educação - ANPED tratavam dessa temática (Faria, 2006) e, dentre elas, o destaque para as experiências dos meninos é ainda menor. Um silêncio que revela a prevalência dos estudos sobre as mulheres e sobre o feminino nos estudos que tomam o gênero como categoria de análise (Carvalho, 2001). Apesar desse panorama, mais recentemente encontram-se estudos que se debruçam sobre as relações entre a Educação Infantil e as questões de gênero sob novos olhares, privilegiando as análises que tenham como referência as próprias crianças ou as masculinidades adultas (Vianna e Finco, 2009; Finco, 2007; Sayão, 2007; Gomes, 2006; Gobbi, 1997).

Esse interesse é fundamental para aprimorar as práticas pedagógicas na Educação Infantil e para contribuir com a construção de experiências mais democráticas e respeitosas no que diz respeito às questões relativas ao gênero e à sexualidade de profissionais e crianças. Louro (2008:8) afirma que:

a construção dos gêneros e das sexualidades dá-se através de inúmeras aprendizagens e práticas, insinua-se nas mais distintas situações, é empreendida de modo explícito ou dissimulado por um conjunto inesgotável de instâncias sociais e culturais.

Assim, as reflexões sobre o modo como as instituições de Educação Infantil colaboram na construção das relações de gênero e de sexualidade das crianças merecem ser incluídas entre as dimensões estruturantes das propostas pedagógicas. Entretanto, para que essa visão se fortaleça, é preciso conceber o processo de desenvolvimento infantil como algo marcado pelas experiências sociais e culturais vivenciadas pelas crianças (Vygostky, 1984; 
Meninos na Educação Infantil

Wallon, 1971). A adoção dessa perspectiva para a compreensão do desenvolvimento humano, ao lado dos estudos feministas e de gênero, reforça a crítica à biologização da sexualidade $e$ a conseqüente naturalização dos modos de ser feminino $e$ masculino. Conforme Louro (2007), lidar com o conceito de gênero significa opor-se a essa naturalização.

Problematizar a noção de que a construção social se faz sobre um corpo significa colocar em questão a existência de um corpo a priori, quer dizer, um corpo que existiria antes ou fora da cultura. A identificação ou a nomeação de um corpo (feita no momento do nascimento, ou mesmo antes, através de técnicas prospectivas) dá-se, certamente, no contexto de uma cultura, por meio das linguagens que essa cultura dispõe e, deve-se supor, é atravessada pelos valores que tal cultura adota. Nesse sentido, seria possível entender, como fazem algumas vertentes feministas, que a nomeação do gênero não é, simplesmente, a descrição de um corpo, mas aquilo que efetivamente faz existir esse corpo - em outras palavras, o corpo só se tornaria inteligível no âmbito da cultura $e$ da linguagem. (Louro, 2007:209)

Para muitas crianças, a instituição escolar é o primeiro lugar público que freqüentam com regularidade, tendo aí a possibilidade de vivenciar experiências culturais distintas das ofertadas pelo ambiente familiar. A centralidade dessa experiência no conjunto das vivências e relações das quais meninos e meninas participam nos primeiros anos de vida torna relevante a investigação e análise desse contexto educativo também por meio da perspectiva que considera o gênero uma dimensão estruturante das relações sociais. Nessa direção, o presente trabalho visa conhecer o que pensam educadoras infantis sobre sua prática com os meninos e as meninas, destacando os primeiros. 
Isabel de Oliveira e Silva e Iza Rodrigues da Luz

A pesquisa foi realizada em uma instituição de Educação Infantil pública de Belo Horizonte ${ }^{1}$ e teve como objetivo analisar a questão do compartilhamento entre família e escola, dos cuidados e da educação das crianças de 0 a 3 anos. Nas entrevistas, as visões das educadoras sobre seu papel no processo de construção das identidades $e$ das subjetividades das crianças eram um elemento no conjunto das questões relativas ao compartilhamento. $\mathrm{O}$ fato das entrevistas não terem como objetivo direto a investigação sobre as questões de gênero revelou-se importante, porque permitiu que identificássemos a presença de concepções contraditórias com as práticas, assim como que as próprias entrevistadas tomassem consciência dessas contradições. Ou seja, na descrição das práticas com as crianças, os sentidos das diferenças de experiências vividas por meninos e meninas emergiam em resposta a questões mais gerais do cotidiano do trabalho na instituição. ${ }^{2}$

Assim, buscamos captar, numa perspectiva fenomenológica, os sentidos ${ }^{3}$ e significados que as educadoras atribuem às diferenças entre meninos e meninas.

A análise das manifestações das educadoras acerca das diferenças por elas observadas nos comportamentos dos meninos e das meninas permitiu identificar elementos de uma concepção de masculino (e de feminino) que orienta suas práticas $e$ intervenções no cotidiano das relações com as crianças.

\footnotetext{
1 A realização da pesquisa contou com a autorização da Secretaria Municipal de Educação e da direção da Unidade Municipal de Educação Infantil pesquisada. Foi entregue uma cópia do projeto nessas duas instâncias e feitos os esclarecimentos acerca dos objetivos e da metodologia da pesquisa. As educadoras foram consultadas previamente e esclarecidas sobre o uso dos dados obtidos por meio das entrevistas e das observações, assinando o Termo de Consentimento.

2 Os elementos analisados neste texto foram obtidos por meio de entrevistas com educadoras e coordenadora de um dos turnos.

3 Entendemos por "sentido" o olhar que "tem por objeto a própria coisa", no nosso caso, as relações de gênero. E por significado, o "olhar que visa o sinal da coisa”, ou seja, o que está para além das relações de gênero (Jovilet, 1975).
} 
Meninos na Educação Infantil

Abordaremos uma das dimensões desse problema: a que discute a experiência dos meninos na Educação Infantil a partir das finalidades expressas para essa etapa da Educação Básica, tendo como eixo a noção de cuidado. Discutiremos, então, os olhares das educadoras sobre as experiências das crianças na escola (e fora dela), procurando apreender/explicitar as concepções subjacentes a eles e suas relações com as condições de formação inicial e continuada das educadoras, bem como com o conjunto das experiências sociais desses sujeitos.

\section{Gênero e Educação Infantil:}

educadoras, meninos e meninas no ambiente institucional

Ao analisar as experiências de educadoras, de meninos e de meninas em uma instituição de Educação Infantil, Neves (2008) entende as relações entre gênero e identidade na infância como um

momento essencial de apropriação e reconhecimento da fala do outro, ou seja, momento de apropriação da cultura, ou de um mundo para o qual a linguagem se dirige.(...) Assim, as relações de gênero não são apropriadas pelas crianças em si mesmas, mas em um horizonte para o qual essas relações apontam, sendo suas identidades forjadas nesse processo (Neves, 2008:149-150).

O ambiente da instituição de Educação Infantil é concebido e organizado por mulheres cujas concepções informam o conjunto das relações que ali se estabelecem. As representações de feminino e de masculino com as quais as crianças se relacionam são, em grande medida, as representações de suas educadoras (Debortoli, 2008; Neves, 2008). Entendemos, no entanto, que as crianças não apenas reproduzem as representações e práticas dos adultos, mas interagem, negociam e, em muitos casos, transgridem regras impostas. Vianna e Finco (2009) evidenciam a necessidade de refletir sobre as crianças que transgridem os 
modelos padronizados de masculinidade e feminilidade já que seus comportamentos sinalizam novas possibilidades de construção das relações de gênero.

Diferentes estudos (Vianna e Finco, 2009; Neves, 2008; Finco, 2007; Gomes, 2006) evidenciam que as educadoras proporcionam aos meninos e às meninas experiências distintas ancoradas nos modelos de masculinidade e feminilidade padronizados em função de uma questionável naturalização do que é "mais adequado" para cada sexo e repreendendo o que consideram inadequado.

Neves (2008) constatou a exclusão dos meninos de determinadas situações. Em suas observações, percebeu que momentos de rica interação entre as educadoras $e$ as meninas, como a organização dos ambientes, em geral, não são compartilhados com os meninos. Nesse caso, as concepções de masculino e feminino que orientavam as educadoras observadas remetem a papéis padronizados do homem e da mulher na nossa cultura. Em geral, tais situações são analisadas do ponto de vista do reforço do lugar subordinado da mulher - o que é também verdade - mas, considerando as possibilidades de interação $e$ experiências, os meninos encontram-se na condição de excluídos.

Neves oferece ainda outro elemento, relativo aos cuidados com as crianças, no qual os meninos são excluídos de situações que evidenciam relações afetivas, de prazer da educadora em cuidar do corpo da criança - no caso das meninas - bem como marcadas pela possibilidade de construção de uma imagem positiva de si e de aprendizagem do auto-cuidado.

Os meninos são, da mesma maneira, excluídos de um momento de cuidado que ocupa um lugar de destaque na rotina institucional: pentear o cabelo. Nas entrevistas com as educadoras, evidencia-se o orgulho com o cuidado com o cabelo das crianças, ou melhor, das meninas. Observando algumas educadoras pentearem as meninas, fica impossível não pensar em uma criança brincando com sua boneca, escolhendo penteados, fazendo trancinhas... (Neves, 2008:158). 
Meninos na Educação Infantil

A autora destaca que, mesmo em relação às meninas, o sentido dessas experiências precisa ser problematizado, pois, em geral, não se pergunta a elas qual penteado desejam, por exemplo. Embora identifique que essa prática, presente na rotina diária, reveste-se de um significado pessoal para o adulto, um "momento isolado da educadora consigo mesma", por outro lado, elas mostram-se amorosas e cuidadosas. E é dessa experiência amorosa e de cuidado que os meninos não participavam. Entrevistando as meninas que vivenciam essa experiência, a autora identificou que, para elas, "não é o penteado em si que é o mais importante, mas, sim, ser cuidada e tocada pela educadora, havendo uma comunicação corporal em jogo da qual as crianças se apropriam" (Neve, 2008:159). Quanto aos meninos, a autora complementa:

Não estamos falando aqui de necessidades que devem ser atendidas com o cabelo sendo penteado exclusivamente por uma questão de higiene e obrigação. Estamos, assim, no campo do desejo e do envolvimento, do toque corporal e afetivo, do cuidado e da vaidade. Ou seja, o cabelo curto não precisa ser penteado, mas esse fato não constitui um obstáculo para que os meninos não sejam tocados por suas educadoras (Neves, 2008:159).

Parece-nos especialmente importante analisar esta questão do ponto de vista das necessidades, dimensão fortemente associada às práticas de cuidados em geral, particularmente com crianças pequenas. Pela análise acima referida, percebe-se que as visões de feminino e de masculino orientam as educadoras na identificação das necessidades dos meninos e das meninas, em que a dimensão afetiva e do toque corporal, no cuidado com os cabelos, não é apreendida como necessidade para além das características de tamanho de cabelos que precisam ou não ser arrumados. As diferentes formas e sentidos do ato de cuidar dependem da capacidade de interação com o outro e de identificar as suas necessidades. Essa capacidade, social $e$ 
Isabel de Oliveira e Silva e Iza Rodrigues da Luz

culturalmente construída, supõe aprendizagens de conceitos $e$ habilidades oriundos de diferentes campos do conhecimento (Maranhão, 2000).

Em nossa pesquisa, tais elementos se evidenciaram, mostrando como as concepções, oriundas das experiências sociais mais amplas, nas quais as educadoras constroem suas concepções de masculino e de feminino, se fazem presentes nos cuidados prestados aos meninos $e$ às meninas, bem como se sobrepõem a conhecimentos adquiridos em processos de formação realizados no âmbito das próprias instituições de educação infantil. $\mathrm{O}$ caso de um menino e uma menina que são irmãos e freqüentam uma das instituições pesquisadas é ilustrativo dessa questão. Mariana e $\operatorname{Marcos}^{4}$ são irmãos e, na época da observação do cotidiano da instituição de Educação Infantil, estavam com 2 e 3 anos, respectivamente. Nas entrevistas com as educadoras, mesmo com as que não haviam sido educadoras dessas crianças, o caso delas era mencionado espontaneamente diante de questóes relativas às dificuldades enfrentadas no trabalho, especialmente no que se referia às relações com as famílias das crianças. De acordo com depoimentos das educadoras, essas crianças são filhas de uma mãe jovem, usuária de drogas, cujo estilo de vida caracterizava-se por negligência com a própria saúde e com a dos filhos, bem como com os demais cuidados com as crianças. Diversas situações de negligência foram relatadas pelas educadoras entrevistadas, mas os exemplos $e$ a indignação expressos por elas em relação aos comportamentos dessa mãe foram todos referidos à menina. De forma distinta, as manifestações sobre as conseqüências dessa situação para o menino necessitavam de estímulo. O silêncio em relação ao menino pode ser interpretado de diferentes maneiras. Talvez as situações que se manifestaram na instituição em relação à menina, um pouco mais nova, tenham sido mais chocantes como o caso de ausência dela durante vários dias e, quando voltou, por determinação do Conselho Tutelar, apresentava

4 Os nomes citados neste artigo são fictícios. 
Meninos na Educação Infantil

assaduras em estágio avançado, evidenciando negligência com os cuidados básicos no ambiente familiar.

Mas outros elementos de preocupação das educadoras com relação à proteção dessas crianças também foram mencionados, sempre privilegiando a menina como exemplo a ser descrito. As educadoras informaram (por exemplo) terem conhecimento de que a mãe se envolvia com homens diferentes a cada dia e, para manter o vício, encontrava-se em um perigoso universo de relações. Nesse caso, sempre manifestavam sua preocupação, em primeiro lugar, com a menina, que estaria exposta a essas situações enquanto esteve sob a guarda da mãe. Todas manifestaram alívio quando Mariana foi assumida informalmente por uma tia da mãe das crianças, o que não ocorreu com Marcos. Esse fato não apareceu como objeto de preocupação das educadoras. A mesma situação se verificou em entrevista com a atual responsável por Mariana, que declarou seu apego à menina e sua enorme preocupação com os riscos a que estava exposta na companhia da mãe, justamente por ser menina.

Essa experiência de cuidado, proporcionado ou desejado pelas educadoras em relação às meninas e não com a mesma intensidade em relação aos meninos, parece evidenciar que, em relação ao menino, relativizam as conseqüências da negligência familiar. Da mesma forma, conforme identificado por Neves (2008), as necessidades de afeto dos meninos não pareciam entrar nas referências das educadoras. Percebemos, também neste caso, uma imagem de masculino e de constituição do sujeito masculino desprovida da necessidade de cuidados básicos, ou, pelo menos, suavizada, se comparada com o pretendido para as meninas.

As situações de brincadeira configuram-se como importantes momentos de interação entre as crianças, de cuidados (entendidos de forma ampla) e de educação (também em uma compreensão ampliada) por parte das educadoras, o que inclui a constituição das identidades, a construção das imagens de si e dos outros como meninos e meninas. Gomes (2006:40), ao investigar a construção do masculino $e$ do feminino no processo de cuidar de 
crianças na Educação Infantil, constatou que, mesmo durante as brincadeiras, as educadoras mantêm a vigilância de modo a garantir o cumprimento das normas sociais que dizem respeito à conduta desejável para cada sexo. Os riscos, inovações e exposições exageradas são permitidos aos meninos, enquanto as meninas, tidas como frágeis e delicadas, devem se comportar de modo mais contido e dentro das regras estabelecidas para a brincadeira. Essa atitude revela as estratégias utilizadas para imprimir nos corpos das crianças os significados de gênero desde muito cedo, pondo em curso um processo de masculinização e de feminilização responsável por torná-las "moleques" ou "mocinhas" (Finco, 2007).

Debortoli (2008:85) chama a atenção para as ambivalências presentes nas ações das educadoras no que tange à compreensão sobre os lugares sociais reservados ou não aos homens (e, conseqüentemente, às mulheres) $e$ como se manifestam no cotidiano das relações com as crianças. Realizando observações em uma creche comunitária, o autor reproduz a fala de uma professora que, para orientar o comportamento das crianças no espaço da instituição diz: "cozinha não é lugar de criança, nem de homem". O autor analisa essa fala na perspectiva de Mauss $(1971)^{5}$, segundo a qual o processo de instauração de condutas passa pelo ordenamento dos corpos e das relações que vão sendo aprendidas, "demarcando lugares sociais de crianças e adultos, meninas e meninos".

Nesse caso, assim como no exemplo trazido por Neves (2008), verifica-se a exclusão dos meninos de determinadas experiências, ainda que no plano discursivo. $\mathrm{O}$ autor revela, no entanto, a percepção de que, no conjunto das experiências das educadoras na instituição de Educação Infantil, há um dinamismo que expressa diferentes concepções em diferentes tempos $e$ espaços institucionais e de relações com as crianças. Ele identifica, por exemplo, situações em que, diante da expressão de

5 MAUSS, Marcel. Sociologia y antropologia. Madrid, Tecnos, 1971. 
Meninos na Educação Infantil

estereótipos e preconceitos por parte das crianças, a educadora intervém, indicando que meninos e meninas podem brincar juntos, experimentar diferentes papéis, tocando em questões que envolvem as relações gênero e outras diferenças. No entanto, o autor conclui que, no contexto institucional, os espaços, os tempos e seus signos não oferecem oportunidades de sua ressignificação, não proporcionando oportunidades de intervenções intencionais, complexas, com novos sentidos e maneiras de agir segundo um projeto cultural.

Em nossa pesquisa, as educadoras também manifestaram ambigüidades que expressam os conflitos entre as reflexões eventualmente realizadas em processos de formação continuada, oferecidos pela Secretaria Municipal de Educação, em que essas questões são tocadas em alguma medida, e sua experiência social, aquela em que elas próprias constituíram sua identidade feminina, informada, também, pelas visões sobre o masculino. As descrições que emergiram das respostas das educadoras a questões relativas à organização do trabalho com as crianças evidenciam também as contradições ou ambigüidades encontradas por Debortoli.

Ao falar sobre a prática pedagógica com as crianças de 3 anos, Fabíola enfatiza a disponibilidade de brinquedos e de sucatas, objetos que permitem brincadeiras de faz-de-conta:

[Temos] muito brinquedo, muita sucata. (...) A sucata, ela permite brincar o faz -de -conta (...), e eles [meninos $e$ meninas] adoram brincar que são mamãezinha, eles fazem comida para a gente.

Na seqüencia dessa fala, Fabíola se corrige, lembrando que a participação dos meninos é diferente - eles participam da brincadeira sendo servidos pelas meninas:

Tem dois meninos só aqui na sala. Você vê como papéis aqui são diferenciados: eles não brincam de fazer comidinha como as meninas brincam. Geralmente, as 
Isabel de Oliveira e Silva e Iza Rodrigues da Luz

meninas fazem a comida e dão para eles comerem (Fabíola, entrevista em 03/12/2007).

Fabíola evidencia uma reflexão a respeito da reprodução de estereótipos, ao mesmo tempo em que parece tomar isso como algo "natural": você vê como os papéis aqui são diferenciados. Indagada sobre como se posiciona diante dessas situações, declarou:

A gente tenta... a gente não... vou falar de mim. Eu tento sempre fazer o seguinte: quando as meninas estão fazendo a comidinha, por exemplo, eu chamo os meninos para ajudar, porque eu não gosto muito de distinguir essas funções não, por exemplo: quando os meninos pedem o velotrol, eu dou o velotrol rosa para os meninos só para ver a reação, e eu fico super feliz quando eles pegam e não estão nem aí se é rosa, azul, verde ou amarelo. Pega e vai brincar numa boa, e eu acho bacana isso, quando as meninas estão fazendo a comidinha, vem aqui olhar, ajudar a fazer o suco de laranja, ela faz o arroz, e você faz o suco de laranja, e ele vai e faz, se a gente chama (Fabíola, entrevista em 03/12/2007).

Sua fala mostra que não se trata de uma reflexão coletiva, presente no projeto institucional de educação das crianças, semelhante à situação identificada por Debortoli ao analisar a ausência de condições institucionais que viabilizem um projeto cultural de transformação das experiências de meninos e meninas. Para Fabíola, o lugar dos meninos é o da ajuda às meninas que, no faz de conta, se encarregam da função mais nobre da cozinha - fazer o arroz - enquanto a eles se solicita fazer o suco de laranja. Ao lado da clara situação de reprodução do lugar feminino nas brincadeiras das crianças, podemos interpretar, do ponto de vista dos meninos, sua condição de subordinação na experiência de brincadeira em questão, na medida em que as ações são tidas como do universo feminino. Mesmo o exemplo do velotrol rosa 
Meninos na Educação Infantil

que, segundo Fabíola, oferece aos meninos para ver sua reação, torna evidente que a inclusão dos meninos em outras possibilidades de ação ocorre em um jogo cujo domínio é exclusivo do adulto. Essa mesma educadora explica a divisão espontânea de tarefas - as meninas fazem comidinha e servem aos meninos - nas brincadeiras de casinha, como algo que vem de casa.

Diante da mesma questão relativa à prática pedagógica $e$ aos recursos existentes, Cristina, outra educadora entrevistada, descreve os brinquedos disponibilizados às crianças de 1 ano com as quais trabalha:

Nós temos brinquedos pedagógicos. No início, é aquele brinquedinho de borracha, para morder... chocalho. Agora, nós já estamos pegando outros brinquedos para começar a fazer encaixe. Temos (...) carrinho, já tem também boneca, que as meninas já estão começando a ninar, já estão aprendendo a ninar as bonecas (Cristina, entrevista em 31/10/2007).

Essa fala é paradigmática da visão sobre as experiências femininas, na medida em que evidencia o processo esperado: já estão aprendendo a ninar bonecas. Perguntada se os meninos não brincam de boneca, ela responde:

Só as meninas, a gente não dá [bonecas aos meninos] não. Nós temos essa... [risos] como que fala... preconceito. Nós não estamos ensinando isso para a criança, mas parece que sim: as meninas já vão nas bonecas e os meninos vão no carrinho, mas a gente deixa, fala assim: vamos brincar junto, famílias, vamos lá, o pai, mas eles vão mais no carrinho, sabe? [risos].

A educadora evidencia certa reflexão a respeito de sua prática, ao afirmar que, embora não tenham a intenção de ensinar os papéis tais como se apresentam nesse relato, reconhece que, de 
Isabel de Oliveira e Silva e Iza Rodrigues da Luz

fato, estão ensinando formas estereotipadas de ser menino $e$ menina, na medida em que não intervém de maneira sistemática nessa questão. Os sorrisos durante sua fala (e sua postura corporal, observada durante a entrevista e registrada em diário de campo) parecem ser indícios de certo constrangimento, pois, a pergunta da pesquisadora, pelo simples fato de ter sido enunciada, dá sinais de outras possibilidades de ação educativa que ela compreende, mas que reconhece não conseguir efetivar. Sua fala, na seqüência da mesma entrevista permite essa interpretação:

Pesquisadora: Mas você acha que é porque que eles escolhem assim?

Cristina: Eu não sei, talvez é até nós que possamos... até mudar, começar nova prática, colocar os meninos para brincar de boneca, e as meninas de carrinhos, talvez a gente está desenvolvendo esse lado, mas a gente não está desenvolvendo preconceito. Talvez pode ser em casa (...) começam com aquela [prática] de não vestir rosa, não vestir azul, já começa sem perceber, mas já estão nessa coisa, de que não existe isso mesmo.

Perguntada sobre se ela $e$ as demais educadoras da instituição têm tido oportunidades de refletir a respeito dos significados que as práticas cotidianas na Educação Infantil adquirem na formação dos meninos e das meninas, Cristina indica que tais oportunidades existem e reconhece que a força da cultura na qual está imersa impede as mudanças em sua prática:

Já. Nós já refletimos. A gente já leu sobre essa..., nós já lemos, nós temos formação. A gente já leu sim. Eu não sei se é cultura, a gente, até sem perceber, começa a pegar boneca para as meninas, a gente faz isso também, pega carrinho para os meninos. Mas nós já refletimos, mas essa cultura é difícil. 
Meninos na Educação Infantil

Cristina e Fabíola expressam contatos com reflexões a respeito das diferenças e dos estereótipos sexuais, inclusive porque os questionamentos às concepções dominantes de masculino $e$ de feminino são, também, parte da cultura contemporânea da qual elas participam. Mas, no que tange às visões a respeito do masculino, Cristina revela quanto é mais difícil desfazer práticas arraigadas, tanto nas experiências familiares, quanto na prática profissional. Referindo-se à sua condição de mãe de um menino $e$ de uma menina (10 e 15 anos respectivamente), declara: "Eu não sei. Eu como mãe, eu não sei, queria começar a brincar, menina de carrinho até vai, mas menino de boneca..." (Cristina, entrevista em 31/10/2007).

Provavelmente, a imagem construída a respeito da pesquisadora a tenha impedido de concluir a frase, mas as reticências captadas na entonação conferida à sua fala indicam, claramente, que o esforço de mudança com relação aos meninos teria que ser bem maior. A apreensão de sua experiência como mãe permite identificar com maior clareza a força do projeto cultural no qual essa educadora constrói suas concepções $e$ práticas educativas:

Pesquisadora: Então, com as suas crianças, você acha que foi criado mais nesses padrões, nesse estereótipo de papel de homem, papel de mulher?

Cristina: Eu acho que ainda está sendo criado assim. Eles estão com 15 e 10 anos, então você vê que a minha menina com 10 anos, eu estou olhando essa outra cultura e depois, também, vejo a cultura dos meus pais. Eu tenho 11 irmãos, olha só de quantos, nossa! Pai não deixava nem ficar junto com um menino, como que eu vou mudar essa cultura? Eu tenho que mudar, agora que eu sou educadora, eu leio, eu pesquiso, eu sei que eu tenho que mudar. Mas assim, olhando pela parte das famílias, me colocando como mãe, eu acho que para elas, é meio difícil. Para elas que ainda não têm uma leitura assim do mundo atual, não acompanham... 
Sua reflexão indica o reconhecimento de que ela é produto de uma cultura, das relações sociais nas quais se socializou e nas quais aprendeu/construiu referências sobre feminino e masculino, sobre o permitido e o não permitido a meninos e a meninas. Ela parece oscilar entre a profissional e a mãe, como duas identidades que entram em conflito no que concerne às práticas educativas com meninos e meninas. E é a existência desse conflito que parece torná-la solidária com as famílias das crianças e com suas concepções e práticas educativas com os filhos e filhas. Além disso, Cristina reconhece que a criança não nasce com determinados comportamentos quando ela se indaga: como é que uma criança vai saber isso?

A gente costuma falar que é a criança que traz, mas são os adultos que colocam. Como que uma criança vai saber isso, não é? Esse preconceito é depois. Hoje a cultura está completamente... O homem está ficando em casa e a mulher saindo para trabalhar, o homem está colocando as crianças para dormir, está dando banho. A gente também tem que fazer esse papel de inverter mesmo, essa inversão de mudar.[referindo-se ao seu marido, ela diz]: até para mudar com a minha família eu acho difícil.

Inserindo as concepções e práticas expressas por essas educadoras no quadro de uma compreensão sobre as ações sociais que concebe a ação individual como social, portanto partilhada por outros que, em relações sociais, constituem os sentidos das ações, parece-nos particularmente importante o significado das contradições expressas por essas educadoras em relação aos meninos. Ou seja, as experiências sociais dos meninos e das meninas estão, cada vez mais, marcadas pela experiência escolar de longas jornadas. Nessa direção, o significado das relações e experiências vividas pelas crianças no contexto escolar na construção de suas identidades de meninos e de meninas torna-se ainda mais importante. Ressalta-se que Carvalho (2001), ao investigar o processo de avaliação de meninos e de meninas no 
Meninos na Educação Infantil

Ensino Fundamental constatou que os comportamentos e atitudes dos alunos eram bastante valorizados no momento da avaliação, ficando os meninos, em geral, mais prejudicados por se distanciarem de um modelo exemplar de aluno preconizado pela instituição. A autora verificou que, apesar da avaliação levar intensamente em consideração o padrão de comportamento, não havia na instituição momentos de reflexão e avaliação sobre essa postura e mesmo sobre a influência das relações de gênero no processo avaliativo. Nesse sentido, a ausência da perspectiva de gênero no conjunto das reflexões de educadores e educadoras de diferentes níveis de ensino é um elemento de reforço de outras desigualdades, dentre as quais as escolares, com as conseqüencias individuais e sociais a elas relacionadas.

\section{Considerações Finais}

As características da Educação Infantil, que incluem a convivência, na instituição educativa, entre educadoras e crianças durante longas jornadas nos primeiros anos de vida conferem a essa experiência um lugar central nos processos identitários dos meninos e das meninas.

O olhar sobre a organização das experiências dos meninos, sob o ponto de vista das possibilidades de participação em diferentes situações e relações no ambiente escolar, revelou que há uma dimensão de exclusão que envolve tanto práticas culturais como algumas possibilidades de trocas afetivas, marcadas por concepções do masculino presentes entre as educadoras.

Essa exclusão dos meninos se evidencia na privação de muitas situações de interação afetiva e corporal que as educadoras propiciam às meninas, como as ações de cuidado com os cabelos. Os meninos parecem ser vistos desde muito cedo como menos afetados por situações de risco e abandono, necessitando, portanto, de menor proteção. Isso se expressa, por exemplo, na permissão e mesmo no incentivo a comportamentos mais ousados $e$ arriscados nas brincadeiras, como a literatura tem evidenciado, 
como se eles fossem mais resistentes aos perigos e pudessem, com menor ajuda dos adultos, constituírem-se em sujeitos no mundo. A necessidade de reforçar essa imagem de resistência $e$ força alinha-se às interdições a brincadeiras ligadas ao cuidado com filhos (brincar de bonecas) e ao trabalho doméstico (cozinha, arrumação dos ambientes), evidenciando uma maior resistência em incluir os meninos em espaços $e$ atividades tidas como femininas do que o inverso. Verifica-se, ainda, que a permanência dessas concepções e práticas entre as educadoras das instituições de Educação Infantil reveste-se de certa ambigüidade tanto no cotidiano de suas ações educativas, quanto em situações em que são levadas a refletir a respeito dessas questões. $O$ mesmo ambiente cultural que reforça papéis padronizados permite, também, o exercício da crítica. No entanto, como prática individual, essa crítica não encontra um ambiente institucional que a fortaleça e que favoreça situações intencionais de construção de novos signos em um projeto coletivo de reflexão sobre o papel da instituição de Educação Infantil na constituição das subjetividades masculinas e femininas.

\section{Referências bibliográficas}

BRASIL. Lei de Diretrizes e Bases da Educação Nacional. Lei 9.394, de 23 de dezembro de 1996.

BRASIL. Conselho Nacional de Educação. Resolução n. 1 de 15 de maio de 2006. Institui as Diretrizes Curriculares Nacionais para o Curso de Graduação em Pedagogia, Licenciatura. Brasília, 2006.

CAMPOS, Maria M. Educar e cuidar: questões sobre o perfil do profissional de Educação Infantil. In: BRASIL. Ministério da Educação e do Desporto/Secretaria de Ensino Fundamental. Por uma política de formação do profissional da Educação Infantil. Brasília, 1994, pp.3242.

CARvalHo, Marília Pinto de. Mau aluno, boa aluna?: como as professoras avaliam meninos e meninas. Rev. Estud. Fem. vol.9, n 2 , 
Meninos na Educação Infantil

2001, pp.554-574. [http://www.scielo.br/scielo.php?script=sci arttext\&pid $=$ S0104026X2001000200013\&lng $=$ pt\&nrm $=$ iso $]$.

CRAIDY, Carmem Maria. A política de Educação Infantil no contexto da política da infância no Brasil. Anais do I Simpósio Nacional de Educação Infantil. Brasília, MEC/SEF/DPE/COEDI, 1994, pp.18-21.

DEBORTOLI, José Alfredo de Oliveira. Reflexões sobre as crianças e a educação de seus corpos no espaço tempo da Educação Infantil. Paidéia, nº 4, Belo Horizonte, jan./jun. 2008, pp.79-108.

FARIA, Ana Lúcia Goulart de. Pequena infância, educação e gênero: subsídios para um estado da arte. Cadernos Pagu (26), Campinas-SP, Núcleo de Estudos de Gênero - Pagu/Unicamp, jan./jun. 2006, pp.279-287.

FINCO, Daniela. A educação dos corpos femininos e masculinos na Educação Infantil Educação Infantil. In: FARIA, Ana Lúcia G. de. O coletivo infantil em creches e pré-escolas: falares e saberes. São Paulo, Cortez, 2007.

GoBBI, Marcia. Lápis vermelho é de mulherzinha - relações de gênero, desenho infantil e pré-escola. Dissertação de mestrado, Faculdade de Educação, Unicamp, 1997.

Gomes, Vera Lúcia de Oliveira. A construção do feminino e do masculino no processo de cuidar crianças em pré-escolas. Texto contexto - enferm., vol. 15, n 1 , mar. 2006, pp.35-42.

HADDAD, Lenira. A creche em busca de identidade. São Paulo, Loyola, 1991.

JOVILET, Régis. Vocabulário de filosofia. Rio de Janeiro, Agir, 1975.

LOURO, Guacira Lopes. Gênero, sexualidade e educação: das afinidades políticas às tensões teórico-metodológicas. Educ. rev., $\mathrm{n}^{\circ} 46$, dez. 2007, pp.201-218.

Gênero e sexualidade: pedagogias contemporâneas. ProPosições, vol. 19, n 2, ago. 2008, pp.17-23.

e MARANHÃO, Damaris Gomes. O cuidado como elo entre saúde e educação. Cadernos de Pesquisa, n ${ }^{\circ} 111$, São Paulo, dez. 2000, pp.115-133. 
NEVES, Vanessa Ferraz de A. Gênero, sexualidade e Educação Infantil: conversando com mulheres, meninas e meninos. Paidéia, $n^{\circ} 4$, Belo Horizonte, jan./jun. 2008, pp.147-163.

RocHA, Eloísa Acires C. 30 anos da Educação Infantil na Anped: caminhos da pesquisa. Zero-a-Seis, $n^{\circ}$ 17, jan./jul. 2008 [http://www.periodicos.ufsc.br/index.php/zeroseis/article/view/800/6082].

ROSEMBERG, Fulvia. Caminhos cruzados: educação e gênero na produção acadêmica. Educação e Pesquisa, vol. 27, n 1 , FE-USP, 2001, pp.47-68.

SAYÃO, Deborah. Homens docentes e o cuidado em creches. Tese de doutorado, Faculdade de Educação, UFSC, 2005.

SILVA, Isabel de Oliveira e. Profissionais da Educação Infantil: formação e construção de identidades. São Paulo, Cortez, 2001.

SILVA, Isabel de Oliveira e. Educação Infantil no coração da cidade. São Paulo, Cortez, 2008.

SILVA, Isabel de Oliveira e; LUZ, Iza Rodrigues da; FARIA FILHO, Luciano Mendes de. Grupos de pesquisa sobre infância, criança e educação infantil no Brasil: primeiras aproximações. Revista Brasileira de Educação, vol. $\quad 15, \quad \mathrm{n}^{\circ} \quad 43, \quad 2010$, pp.84-97 [http://www.scielo.br/scielo.php?script=sci_arttext\&pid $=$ S14132478201000 0100006\&lng $=$ pt\&nrm $=$ isso].

VIANNA, Claudia e FINCO, Daniela. Meninas e meninos na Educação Infantil: uma questão de gênero e poder. Cadernos. Pagu (33), Campinas-SP, Núcleo de Estudos de Gênero - Pagu/Unicamp, jul./dez. 2009, pp.265-283.

VigostKi, L. A formação social da mente. São Paulo, Martins Fontes, 1984.

Wallon, H. As origens do caráter na criança. São Paulo, Difusão Européia do Livro, 1971. 